\title{
On the Principles of Resource Consumption Optimization on Microeconomic Level
}

\author{
Petru Stefea, Andrei Pelin \\ West University of Timisoara, Romania
}

\section{Abstract}

In a business environment defined by overproduction, ever increasing competitive pressures, fast technological dynamics, there remain few reliable instruments to be used by managers in order to develop and maintain competitive advantages. Traditionally, manufacturing cost reduction represents one the solution that are most close to the managers in order to counteract the threats coming from a business's environment. In such a context, this paper aims to develop the ways to obtain cost reduction of three types of resources: direct materials, direct labour and manufacturing overhead. The main method used in the article is analytical logic, the objective being to highlight the approaches to be used in order to optimize resource consumption in its different forms. The results of the article focus on the practical ways to increase a manufacturing enterprise's efficiency.

Keywords: Cost optimization, resource consumption efficiency, cost reduction, direct costs, overhead

JEL classification: M21, D24

\section{Introduction}

Today, when global economy has freshly exited a financial crisis coupled with an ever-increasing pressure of resource scarcity, resource consumption management and control represents a paramount issue for any business organization, SME or large corporation alike. Thus the role of cost controller is redefined, so that in many cases, controllers who participate in these continuous cost-reduction programs are helping to remake corporate culture [Institute of Management and Administration, 2006].

In order for the cost controllers to fulfil their mission, it is mandatory to explore the alternative possibilities in order to increase organization's efficiency using any cost reduction sources available.

This paper aims to develop the practical ways to increase a manufacturing enterprise's efficiency beginning from the general observation that manufacturing companies have three main types of costs: direct materials, direct labour and a heterogeneous pool forming the overhead. The behaviour pattern of each of the three costs types is dependent on certain specific factors; therefore their reduction which is the effect of a cost efficiency increase campaign - is obtained by applying customized set of actions.

The paper consists of a methodology section, where the methods used to achieve its goal is described. The following section is presented the results of the methodology application, providing the general cost functions to be optimized for each of the main three operating costs for a manufacturing company and finally in the conclusions and discussions section the results are evaluated and the limitations of the approach are stated.

Following books and articles were used in the process of researching and writing this article: Drury (2001), Ebbeken et al. (2001), Haciuc (1999), Institute of Management 
and Administration (2006), Opriş (1990), Parvu (1999), Radke (1977), Shank (2001), Stefea et al. (2008), Stefea and Pelin (2008, 2008a).

\section{Methodology}

The process of cost reduction can be developed only if there are some cost reduction sources (reserves), if their nature and amount is known, as well as what are the factors that determine these cost reductions and lead to their good use.

The most important of cost management deliverables is improvement of resource consumption efficiency within the business's internal value creating processes. This means the reduction of resource consumption while maintaining the amount of created value, or - ideally, even increasing it. One of the most important conditions that should be met by the cost reduction measures is that their implementation should not lead to negative effects upon products quality or, in general, upon the value delivered to the customers. At the same time, cost reduction solutions should not have negative effects on the company's sales. This means that cost optimization solutions should be durable.

Normally cost reduction measures implementation requires in turn a certain amount of effort, which also has a resource consumption feature. Thus, another criterion that should be met by cost reduction solutions is that of efficiency, i.e. these should imply an effort that is followed by a greater effect so that it could lead to a greater ratio between value created / resources consumed.

The relative priority of cost reduction solutions relates to the fact that some solutions are more important and therefore have a greater priority than others.

The last feature of cost reduction measures concerns their realism. This means that an enterprise should be capable of delivering the effort implied by a particular cost reduction solution, and this effort should unequivocally lead to the desired effect in terms of cost reduction durability and efficiency.

The main method used in the article is analytical logic, the objective being to highlight the approaches to be used in order to optimize resource consumption in its different forms. Thus, we begin by defining the general formula for each of the three types of operating costs - direct materials, direct labour and the overhead - and thereof we develop aspects like the correlation of each cost type to the value it creates, the underlying analytical factors for each cost type as well as different practical methods to obtain cost reduction by managing those primary factors. The generalization of these cost reduction measures leads to the formulation of principles to be used for optimization of resource consumption on a microeconomic level.

\section{Results}

Direct material cost optimization

In the majority of manufacturing industries, direct materials represent one of the main cost components in terms of complete unit cost.

Thus the general formula for direct material unit cost is presented below:

$$
\frac{C_{M}}{Q f}=\frac{\sum_{i=1}^{m} c_{M i}}{Q f}=\frac{\sum_{i=1}^{m} q_{M i} \times p a_{M i}}{Q f}
$$

where:

CM - direct material cost;

qMi - the "i" type material quantity consumed in manufacturing processes; 
paMi - the complete price of acquisition price for „i" type material (including cost of transport, manipulation, storage etc.;

$\mathrm{m}$ - total number of material types is in manufacturing processing;

Qf - total quantity of products manufactured.

Direct material cost is a "useful" one, meaning that there is a direct causal relationship between raw materials and auxiliary materials consumption and the value created for the end user, represented by the product or service purchased.

Raw and auxiliary materials per unit cost reduction could be obtained, using formula (1), either by reduction the volume of materials consumed or by decreasing their purchasing unit price. As the purchase price for raw and auxiliary materials is formed in the area of transfer prices between the enterprise and its providers of materials, the cost management has no information whatsoever to mitigate this factor. Reduction of purchase prices could be obtained however by controlling market prices as well as other components of the purchase price, such as transport, manipulation and storage of direct materials. This component of model (1) could be controlled rather through expense management, as it operates with instruments and information required to deal such issues.

Thus, the only factor that the direct material cost reduction could be obtained through cost management is represented by specific consumption of materials per unit of product. The quantity of raw and auxiliary direct materials for a given "i" component ( $\mathrm{qMi}$ ) is calculated by multiplying the specific consumption of that material per unit of product (csi) with the quantity of manufactured products (q):

$$
q_{M i}=\sum_{i=1}^{n} q \times c s_{i}
$$

The reduction of specific consumption of direct materials represents the only way that the reduction of direct material cost could be obtained, from the perspective of cost management. On the other hand, the reduction of direct materials specific consumption per unit of product should be done in such a manner that the quality of the product is not affected.

The level of specific consumption that usually represents the basis for comparison is the consumption normative, a value that is calculated through technological methods for each specific type of product, and, at the product level - for each specific type of material consumed.

The consumption normative contains the direct materials that are imbedded in the finished product, as well as other components given by the specific method of its determination. In these circumstances, the most plausible reduction of specific consumption should be firstly by putting to good use as much of the purchased materials as possible, meaning the reduction up to elimination of technological material losses and of all other consumption components that don't make it to the end product. Such an objective could be reached usually either by reorganizing all the internal material management and consumption processes such as storage, manipulation, extern and internal transport etc. or by bringing changes to the technological level of the manufacturing equipment or different manufacturing processes.

Reduction of the material cost component that is integrated into the finished product is based, primarily upon the reduction of scraps and wastes ratio through implementation of a process and product quality control system. The second possibility of material quantity consumption is through redesign of products, their technological improvement. 
All solutions for direct materials cost reduction should be arranged in an order given by the criterion of the effort their implementation requires as well as that of the effect on the efficiency improvement. The enterprise management decides the implementation of one or another from the range of identified solutions bearing in mind mainly the overall business strategy. If the strategy implies an aggressive attitude towards market, then the enterprise should focus on generating competitive edge. Advantages compared to competitors could be based either on differentiation (technological, qualitative etc.) or on low cost. The most radical advantages, both of differentiation and low cost types are obtained through major investment in research \& development and implementation of the latest manufacturing technologies. As the cost of identified solutions decrease, normally, the effects of those solutions upon cost levels as well as their durability and efficiency are lower.

However, an enterprise should focus its attention upon the most basic and cheap solutions for direct material cost reduction: improvement of organizational issues related to processes of direct materials management and consumption

\section{Direct labour cost optimization}

The direct labour cost depends upon many factors. Based on model (3), this type of cost is influenced by allowed time (tn) and hourly wage (salary) rate (sh) of each "j" category of direct labour that contributes to a certain product manufacturing:

$\frac{C_{D M}}{Q f}=\frac{\sum_{j=1}^{k} C_{D M j}}{Q f}=\frac{\sum_{j=1}^{k} Q f \times t n_{j} \times s h_{j}}{Q f}=\sum_{j=1}^{k} t n_{j} \times s h_{j}$

where:

CDM - direct labour cost;

Qf - volume of production;

tn - allowed time;

sh - hourly wage rate;

$\mathrm{k}$ - total number of direct workers categories.

Symmetrically with the case of direct material costs, direct labour cost depends on to essential factors: the volume of labour consumed per each unit of product and the hourly cost of labour.

The second factor - wage per hour of direct labour - makes a less controllable factor for management, because it depends upon the conjuncture on the labour market on the one hand, and upon the results of management negations with labour unions, that take the form of an official collective employment contract as well as negotiation between management and each employee that comprise into an individual employment contract. Thus the problem of optimization for this cost factor is, as in the case of purchasing prices for direct materials, a matter for expense management. Reduction of wages is a very unpopular measure of cost control from the employees' point of view. From the perspective of this factor for cost efficiency improvement the best approach is to correlate as close as possible the value of wage to the productivity of each employee.

Thus, from the perspective of cost management, the only factor that could be used to reduce direct labour cost is by reducing allowed time. The allowed time is formed from several components, out of which the time used strictly for productive purposes is only a part, usually the most important one as a ratio. Allowed time reduction could be obtained by reducing or even eliminating non-productive time, or by reduction of the productive time component itself. 
Reduction or elimination of non-productive time, as well as optimization of productive labour time can be obtained by improvement of labour processes on the one hand or through improvement of technological level of manufacturing equipment on the other. Substitution of manufacturing systems with superior ones from the technological point of view (mechanization of manual processes, automation of mechanized processes or even implementation of computer integrated manufacturing) leads not only to reduction of non-productive and productive labour time components, it even eliminates some of these. Thus, in some cases, automated operations eliminate the need for a human presence or even human supervision of the manufacturing processes. Obviously, the cost of technological replacements is as high as the technological difference between the old and new system are deeper.

\section{Overhead cost optimization}

Indirect manufacturing costs, also called manufacturing overhead, are composed of a large number of heterogeneous cost components, that could not be traced directly to the products obtained or services rendered. Thus, in the process of establishing unit cost, different costing methods use different techniques in order to allocate the indirect costs to the cost objects.

In the case the criteria of overhead allocation are not exact enough, indirect cost management should be concerned exclusively with their overall value. On the other hand, if costing method provides a reliable way for allocation manufacturing overhead to relevant cost objects, then those cost should be managed based on the following formula:

$\frac{C_{I P}}{Q f}=\frac{\sum_{l=1}^{p} C_{I P I}+A_{C I P}}{Q f}=\frac{\sum_{l=1}^{p} q_{l} \times p a_{l}+A_{C I P}}{Q f}$

where:

ql - quantity of resources with relevant proportions within the overhead, reflected by the overhead cost from ,"l" category;

pal - the purchase price of resources that form overhead cost from „l" category;

$\mathrm{p}$ - total number of cost categories with a relevant proportion in total overhead;

ACIP - other indirect cost with low proportions in total overhead.

Thus, the main components of manufacturing overhead cost are detailed by multiplying the material support of each consumed resource with their purchase price or tariff. For instance: for electric energy consumed in manufacturing purposes - quantity is measured in total $\mathrm{kWh}$ consumed, and purchase price is the tariff which is paid to the electricity providing company for each kWh. All the elements that have negligible proportions of total overhead cost are considered only on overall level.

As in the case of direct costs, in the majority of instances, the purchase price for indirect resources represents a factor that leaves little to management to use for cost optimization.

On the other hand, the quantity of resources consumed represents a factor by optimization of which could be gained some cost reduction. In this sense there should be studied the relationship between the resource consumption and the value it creates. From this point of view, Activity Based Costing provides the most exact information. This is due to the fact that a large amount of total types of indirect resources relative to cost object are direct relative to activities. From the perspective 
of value creation chain, activities create value, consume as well resources. Practically, by solving the transition of resource consumption to each cost object through the activities developed within the enterprise, there could be developed the solution for overhead cost reduction.

Reduction of indirect resource consumption quantity is obtained based upon the way these contribute to value creation. From this point of view of overhead costs could be split into two categories. The first category include the indirect costs that could be identified upon each cost object, but their direct tracing with the cost objects is not economically feasible. For instance: cost of fuels consumed for internal transport, when each vehicle transports different cost objects; cost of production energy, when there no energy consumption meters for each equipment which separately registers energy consumption for each cost object.

The second category contains the real indirect costs that have no relationship whatsoever to the cost objects. For instance: the energy cost of lighting the manufacturing premises, the labour cost of quality control department employees when it is common to the entire business.

Thus, indirect costs that are from first category could be analysed approximately in the same manner as direct costs, the only difference being that their optimization concern not the per unit cost but the cost related to the activity. Their reduction implies optimization of that activity either through organization change or technological change.

On the other hand, real indirect costs could be approached exclusively by their overall value. The planned value of overhead is given in overhead budget on a global level. In these circumstances, the sole possibility for overhead reduction is associated to their step-by-step overall reduction, so that no other quantitative or qualitative performance indicators are affected in a negative manner

\section{Conclusions and discussions}

The measures and solutions for manufacturing cost reduction presented in this paper are structured from the most basic and cheap ones - reorganization of internal processes - to the most complex and expensive ones - replacement of the entire manufacturing system with newer technologies.

Enterprise's management decides upon the structure of measures that can be applied to maintain a continuous cost control, depending both on the extent of deviation of actual costs compared to budgeted ones, as well as depending upon the amount of resources that the enterprise allocates for this purpose. In other words - the cost reduction problem is, at its turn, one of optimization of an effect/effort correlation, in which the effort is represented by the amount of resources required to implement a cost reduction measure, whereas effect is represented by the degree to which costs get effectively reduced.

The main limitation of the paper is given by the very nature of the approach used to develop the results: analytical logic is based on a high degree of generalization of what can be observed within manufacturing enterprises. Thus, in order to apply any of the cost reduction measures stated in this paper in a real company, it should be customized and developed to suite the specific needs and conditions of the enterprise it is designated for.

One possible way to further develop and increase the quality of this paper's results is to use statistical data and construct for each of the cost types a model to measure the correlation to the value created and the effectiveness of cost reduction measures stated above. 


\section{References}

1. Drury, C. (2001), "Costing. An introduction" (4th edition), Thomson Learning.

2. Ebbeken K., et al. (2001), "Costing and Cost Management”, Teora Publishing House, Bucharest.

3. Hlaciuc E. (1999), "Modern costing techniques", Polirom Publisching House, lasi.

4. Institute of Management and Administration (2006), "Cost Reduction and Control best practice", John Wiley \& Sons, New Jersey.

5. Opriş I. (1990), "Cost structure analysis and forecasting techniques", Dacia Publishing House, Cluj-Napoca.

6. Parvu F. (1999), "Costs and decision making", Economica Publishing House, Bucharest.

7. Radke M. (1977), "222 practical measures of cost reduction", Tehnica Publishing House, Bucharest.

8. Shank J. K. (2001), "Cases in cost management. A strategic emphasis" (2nd edition), Thomson Learning.

9. Ştefea P., Pelin A., Brindescu D. (2008), "The Reflection of Enterprise Performance Through Cash Flows", Annales Universitatis Apulensis Series Oeconomica, Universitatea "1 Decembrie 1918", Alba lulia, pp. 244-254, ISSN 1582-5450.

10. Ştefea P., Pelin A. (2008), "Resource consumption optimization through minimization of cash outflows", 4th International Conference Accounting and Management Information Systems (AMIS 2008), Bucharest, Romania, published in "Accounting and Management Information Systems", ISSN 1583-4387, pp. 190.

11. Ştefea P., Pelin A. (2008a), "Cost analysis methodology in a "standard cost" costing environment", Analls of Craiova University - Economic Sciences, Year XXXVII, Vol. 5 No. 365, indexed in RePEc.

\section{About the authors}

Petru Stefea received $\mathrm{PhD}$ in 2001 in accounting at West University of Timisoara, Romania. His main interests are financial statement analysis, company performance analysis and management, company valuation. Mr. Stefea is author of 41 scientific papers published both in Romania and abroad. Mr. Stefea is currently the vicepresident of the West University of Timisoara, Romania. Author can be contacted at petru.stefea@e-uvt.ro

Andrei Pelin received PhD in 2008 in accounting from West University of Timisoara, Romania. His main interests were related to cost analysis and control methods as well as cost-benefit analysis Mr. Pelin is author of 24 scientific papers published both in Romania and abroad. Author can be contacted at andrei.pelin@e-uvt.ro 